\title{
Interventions to improve teaching and learning in first year mathematics courses
}

\author{
Johann Engelbrecht ${ }^{\mathrm{a} *}$ and Ansie Harding ${ }^{\mathrm{b}}$ \\ ${ }^{a}$ Department of Science, Mathematics and Technology Education, University of Pretoria, \\ 0002 Pretoria, South Africa; ${ }^{b}$ Department of Mathematics and Applied Mathematics, \\ University of Pretoria, 0002 Pretoria, South Africa
}

*Corresponding author: Email: johann.engelbrecht@up.ac.za

In keeping with the national mandate of increasing graduates in the sciences in South Africa, a concerted effort in improving the first year experience becomes imperative. First year mathematics courses commonly provide the base knowledge necessary for progression in different degree programmes at university. Success in mathematics courses influences throughputs, retention and graduation rates of various degree programmes. Due to the highly complex and integrated nature of issues pertaining to improving teaching and learning in these courses, a multi-dimensional approach was conceptualized and implemented at the University of Pretoria. This paper reports on the development of a coherent framework, and the process and strategy for improving student success through a number of teaching and learning interventions in the first year mathematics courses, addressing the different dimensions of the framework. The process embarked upon resulted in a coherent, resource-focused approach with a replicable model for similar contexts.

Keywords: first year students; mathematics courses; student success

\section{Introduction}

Learning in the first year of a science degree is regarded as a challenging transitional period for students moving from a high school learning environment to tertiary learning. The difficulties that students contend with during this transitional period and the effects this can have on student success in higher education have been documented in literature nationally [1,2] and internationally.[3] In the past few years, South African and international deliberations in higher education have predominantly focused on matters pertaining to increasing and widening access and participation, [4,5] challenges with student retention and graduation rates, specifically the throughput of black students.[2] Lately, discourses largely concern student success in the first year.[6]

There is evidence that students entering tertiary study suffer increasingly from underpreparedness in mathematics. $[1,7,8]$ Concerns have been raised in different forums on the effects and influence of the first year on academic attainment in subsequent years and the successful completion of studies by students. $[9,10]$ As an attempt to curb the effects of the challenges of transition faced by incoming students, universities have embarked on various strategies to provide support to students and improve student success. The University 
of Pretoria (UP) as a large research-intensive residential university has prioritized student success as a core output as indicated in the institutional strategic plan 2025.[11]

\section{Context}

The science faculty at UP offers courses in a variety of fields that serve as prerequisite, co-requisite and requisite for continuation in different degree programmes and as gateway courses due to their foundational nature. Large class enrolments are prevalent in these courses.

In its attempt to improve student success, a group of courses that were regarded as having a significant impact on student progress and eventual success in their studies were identified, classified as high-impact modules (HIMs).

The HIMs are first year level courses that form the core of the B.Sc. degree with large enrolments. These courses are core courses particularly relevant for specialization that support ease of progression into subsequent years of study - prerequisites for many other courses. The definition of HIMs ensures a distinction between the HIMs and high-risk (or high-stakes) courses so as to avoid ambiguity in the usage of the terms.

The objective with this paper is to offer a framework for interventions in the first year mathematics HIM courses and to position interventions within this framework.

\section{Framework for student success in first year mathematics}

In this section, we use the existing literature and our own experience regarding problems and challenges that students experience to develop a framework that was used as a basis for specific interventions to address the needs of first year students in mathematics.

Lawson et al. [12] did a comprehensive review on good practice in mathematics support centres in the UK and made an analysis of one-to-one support intitiatives. Anthony [13] used qualitative data from lecturers and students to identify factors that were perceived as making the most important contributions to students' academic success in first year mathematics courses. Motivation, active learning, help-seeking, student effort and workload were identified as key factors.

Taking these findings into account, we identified five main categories of challenges that need to be addressed with first year mathematics students.

\subsection{Academic transition - mathematical preparedness}

The increasing gap between university and school is partially due to the fact that the content of the South African school syllabus in mathematics has been reduced or removed in some topics and students enter university with knowledge lacking in these topics. Other topics have been added, making the Grade 12 mathematics curriculum so full that many topics are covered fairly superficially. This is not only a local problem. In the USA, Sutherland and Dewhurst [14] studied the problems faced by a wide range of disciplines and universities. They concluded that:

both schools and universities are straight-jacketed by a mathematics curriculum and examination system which does not adequately prepare students for Higher Education.

Schools place a premium on performance in the Grade 12 examination. Students are awarded bursaries on ground of these results; entrance to university is often dependent 
on these results and schools use these results for marketing purposes. In addition, teachers involved are evaluated on the pass rates of learners in the Grade 12 examination. Preparation for this examination is therefore extensive. A common practice at schools is to work through a multitude of previous examination papers in preparation for the final examination, assisted and encouraged by teachers. This type of examination training is not encouraged at university level and is not suitable preparation for the more conceptual approach followed at university. First year students generally find the approach at university hard to adjust to. They also find it difficult to deal with the volume of work and the pace at which it is presented. They experience a sudden lack of individual attention and find the transition to independent learning problematic.

The approach at university level is not only more conceptual in nature but also, because of the volume of work, there is little opportunity for either repeating problems by working through many previous papers or for examination coaching. There is no immediate solution for the transition from procedural to conceptual thinking and for acquiring skills for problem-solving - it is a process that takes time and requires guidance from a competent lecturer. The formal aspect of mathematics, best seen in formal proof of a theorem, is in line with conceptual thinking. The theorem-proof paradigm is foreign to students entering university. Structuring thoughts in a logical way and using the correct mathematical symbols and terminology to formulate these thoughts are again a skill that needs to be cultivated.

\subsection{Non-cognitive transition}

In a diverse student population, such as at UP, there is a group of students from affluent urban schools with good pre-university preparation, but the majority of students come from rural or township areas where not only the quality of schooling is often poor, but the cultural life is very different from what they experience at university. Students entering university come with personal attributes and other sociocultural characteristics.[15] Many of these students have more problems adapting psychosocially than academically. They have problems related to finances, accommodation, family, friends, time management, study methods and many more.[6,16]

Internationally, research on general student success and the first year experience is growing. A number of theoretical models have been introduced. Examples include

- Transition Theory,[17] in which they differentiate between three types of transitions, namely anticipated transitions, unanticipated transitions and non-event transitions;

- Psychological Model of College Student Retention,[18] in which the focus is on the relationship between the independent variables in the model and student persistence;

- College Readiness Model,[19] defining readiness as consisting of key cognitive strategies, key content knowledge, academic behaviours and contextual knowledge;

- Longitudinal Departure Model,[15] which broadly states that individual withdrawal occurs over a period of interactions between individual members of the academic staff and the social community of the institution.

Authors such as Braxton [20] and Tinto [15] mention family responsibilities, work responsibilities, social support, integration versus isolation and motivation as factors contributing to their non-success. Sedlacek [21] identified the non-cognitive and/or demographic characteristics of students to be used as an admission tool to determine risk and to determine developmental needs. Students' entry characteristics such as gender, racial or ethnic background, socio-economic status, parental education and ability to pay for 
college have an influence on a student's commitment to the goal of graduation and the institution.[16,22]

These theoretical models seek to describe behaviours and classify the variables that relate to the general underlying reasons why a student might leave university before graduation. These models, however, focus strongly on the socio-psychological and cultural aspects of what problems students experience when coming to university. While we fully agree that these problems should be addressed, in our model we consider these issues as part of the problem and our focus is stronger on the mathematical aspects. These sources were tapped for giving the transition initiatives theoretical founding and depth.

Following the classification in Transition Theory,[17] the transition that we address can be considered as anticipated transition. This gives us the opportunity to plan in advance what interventions are needed.

\subsection{Continuous engagement - independent learning, continuous learning, formative assessment}

Students entering university come from a school environment where a tab is kept on the student's progress by both teacher and parents that often results in success at the cost of independent learning. The tertiary environment offers more freedom than the school environment, both academically and socially, putting students at risk of realizing too late that they have failed to keep up with the work and are unable to catch up. Continuous assessment can be used for three different purposes - development and learning, measurement of outcomes and for verifying academic standards.[23] The premise is that although assessment is often the driving force behind a student's academic involvement, care should be taken that assessment should not only be a measuring instrument but also, and especially, a developmental instrument with the purpose of engaging the student. For large group teaching, hand grading of and feedback to assignments and tests have become somewhat of a luxury, to which technology offers a possible solution. The availability of online homework systems offers a suitable platform for engaging the student with the formative assessment component still present but in a secondary role. Learning management systems have online quiz facilities that can also be used for the dual purpose of engagement and assessment, perhaps leaning to the latter. This type of engagement has the added benefit of cultivating independent learning.

\subsection{Readily available support}

In a conceptual subject such as mathematics, availability of support is important. Support to first year mathematics students has become an integral part of the drive to improve the success and experience of the first year. For this purpose, support centres have been initiated at universities.[24] Testimonials of students pay tribute to the value and impact that such available support has had on their academic success.[25] Such centres have large budget implications and are not necessarily feasible but underline the need for support, yet students are not always keen to make use of support.[26] The challenge is to provide support that students both feel comfortable with and that is readily available. This dimension of the framework corresponds to Tinto's [15] Longitudinal Departure Model, underlining the importance of regular interactions between individual members of the academic staff and the social community of the institution. 


\subsection{Repeated exposure - multiple opportunities}

In spite of the emphasis placed on conceptual understanding worldwide, it is not sufficient to understand the concept, you need fluency in applying the ideas. This fluency only comes with repeated exposure. Oakley [27] compares being fluent in mathematics to learning sport:

There is an interesting connection between learning math and science, and learning a sport. When you learn how to swing a golf club, you perfect that swing from lots of repetition over a period of years. Your body knows what to do from a single thought—one chunk-instead of having to recall all the complex steps involved in hitting a ball. [27]

In recent international studies of mathematics achievement, the East Asian students have consistently outperformed their counterparts in western countries. Leung [28] did a study in which he discusses the features of the East Asian mathematics education in contrast to features in the West. He argues that understanding is a continuously growing process and that a student should memorize only after full understanding, if there is a need to memorize at all. Deep understanding of mathematics, including the ability and familiarity to use that understanding in new situations, only comes with repetition, memorization and practice. In agreement with this view, Engelbrecht [29] describes a model in which mathematical understanding grows in depth through repeated exposure. Different students need different extents of repeated exposure to reach the required level of understanding. This has as consequence that some students struggle to complete a course in the prescribed time, also because they are doing other subjects as well and cannot focus only on mathematics. If these 'slower' students are not to fall behind in their progression through their studies, additional opportunities have to be created for them to catch up - opportunities where they can focus only on mathematics.

\section{Interventions in mathematics HIMs}

First year courses in mathematics form part of various degrees in five faculties (Science, Health Sciences, Engineering, Commerce and Social Sciences) in the university supporting progression in many programmes into subsequent years of study. Large class enrolments result in the preferred team teaching approach, meaning that a number of lecturers and teaching assistants are collectively responsible for running the course.

Following the framework, specific mathematics intervention initiatives were introduced, addressing the challenges mentioned in the framework categories.

\subsection{Academic transition - mathematical preparedness}

\subsubsection{A refresher course preceding the first semester}

The mathematics department has been experiencing an increase in the number of students with disparate school backgrounds, including students who have taken a 'gap' year. To address the needs of these students, a one-week refresher course is presented in the recess period preceding the first semester. Basic concepts from the high school curriculum that are applicable to the first year curriculum are revised in this course. Fhloinn and Perkin [30] ran a similar course at Dublin City University and claim that mathematical deficiencies need to be addressed as early as possible in students' university lives. 
Table 1. Pre-test and post-test results in the refresher course.

\begin{tabular}{cccc}
\hline Year & $\begin{array}{c}\text { Number of } \\
\text { students }\end{array}$ & $\begin{array}{c}\text { Average for the test } \\
\text { written before the course }\end{array}$ & $\begin{array}{c}\text { Average for the test } \\
\text { written after the course }\end{array}$ \\
\hline 2006 & 34 & $39 \%$ & $58 \%$ \\
2007 & 92 & $51 \%$ & $68 \%$ \\
2008 & 63 & $47 \%$ & $65 \%$ \\
2010 & 131 & $43 \%$ & $61 \%$ \\
2011 & 96 & $28 \%$ & $56 \%$ \\
2012 & 74 & $39 \%$ & $71 \%$ \\
2013 & 100 & $30 \%$ & $55 \%$ \\
2014 & 82 & $28 \%$ & $57 \%$ \\
\hline
\end{tabular}

This intervention is in line with Conley's [19] College Readiness Model, in particular, addressing the key content knowledge dimension of this model and the contextual knowledge dimension to a lesser extent.

The course has been presented since 2006, and over recent years, there has been an increase in the number of students taking this course despite the fact that students have to pay an additional tuition fee for the course. Results of the tests written before and after the course, shown in the Table 1, indicate that students benefit from this intervention.

It is noticeable that after 2010, there seems to be a dramatic decrease in performance, both in the pre-test and post-test, although the post-test performance stays significantly higher that the pre-test performance. These are students who were subjected to a new education system. The averages for the post-tests are all significantly higher than the averages for the pre-tests, as verified by a $t$-test - all $p$-values are $<0.01$. Although the refresher course serves a fairly small group of students, it is viewed as successful and will continue.

\subsubsection{Adapting the curriculum}

The mathematics department at UP has compensated for the changes in the school curriculum by restructuring the syllabi and where possible has decreased the pace at the beginning of the first year to enable students to adapt easier.

For students in the mathematical field, care is taken to explain the significance of a theorem and the accompanying proof. Burn et al. [31] make a case for just-in-time embedded remediation to improve student learning while using class time efficiently. Following this example, the structure of a proof and the different types of proofs are discussed in detail. In addition, Saturday morning sessions are scheduled in which theorems and proofs are discussed. These sessions are well attended by students across the performance spectrum despite it being voluntary. In the engineering courses, less emphasis is placed on proof. Yet, a number of the stalwart theorems of calculus are isolated, emphasized and proven. The curriculum has been adapted since 2010 and is a continuous process.

\subsection{Non-cognitive transition}

\subsubsection{Focus on 'at risk' students}

Guided by the experience from literature, we used the suggestions made in the theoretical models discussed in the beginning of the previous section [15,17-19] to plan our strategy 
with students' non- cognitive transition. Instruments were developed nationally, institutionally and departmentally to profile 'at risk' students before the start of the academic year, but also on a continuous basis. These are students who are at risk of not succeeding in their studies. Academic preparedness is measured using final school results, results of the National Benchmark Test [32] and on-going academic results at the university. Non-cognitive preparedness (sociological and psychological) is measured using data obtained from the Student Academic Readiness Survey, developed at the university.[16] These instruments provide individual readiness profiles based on a combination of cognitive, meta-cognitive and non-cognitive characteristics. The profile is used to channel students for targeted support into different groups. Students identified as 'at risk' receive comprehensive proactive academic, psychosocial, financial and other supports such as described elsewhere in this paper, but also academic advising and psychological counselling [33] that are integrated and supervised by faculty-based student advisors who are registered educational psychologists. Their performance is closely monitored and regular meetings with the faculty student advisor are based on a prescribed agreement. Depending on their university performance, students can be reclassified and channelled into (or out of) the group of 'at risk' students at any time of the year. The focus on 'at risk' students has been running since 2009 and is an ongoing initiative.

\subsection{Continuous engagement}

\subsubsection{Online homework system - Webassign ${ }^{T M}$}

Webassign $^{\mathrm{TM}}$ is an online homework system accompanying textbooks of the Cengage ${ }^{\mathrm{TM}}$ publishers. The course coordinator compiles assignments from textbook problems in online format that students then have to complete before a due date. Students get immediate feedback alerting them to their competency in a particular topic and there is no time-consuming grading involved. Webassign is used in HIM courses as preparation for tutorial sessions. Webassign compels students to do these problems, whereas, otherwise, the experience is that students may fail to come prepared as there is no control over what they do at home. There is a fee for using Webassign, which in this case is added onto student tuition fees. As with implementing any new system, there are teething problems such as putting the payment system in place, streamlining the login process and getting expertise in setting assignments. Other concerns are raised in [34]. Yet, the system has proven to answer a need and students are positive about using it.

In a survey conducted after the first semester of implementation, $70 \%$ of students recommended use for the following year, whereas in a subsequent survey, after another two years of implementation and after streamlining usage, $88 \%$ of students recommended Webassign for future use. Performance in the Webassign assignments correlates well with the semester mark - in a group of 866 students in the mainstream mathematics course of 2014, a Pearson correlation coefficient of 0.57 was obtained, which is significant on a $1 \%$ confidence level. In the same course, students who had a positive gain from the first (of two) term tests to the second term test had an average mark of $82 \%$ for Webassign, whereas students with a negative gain had an average of $70 \%$ for Webassign. Although it is difficult to quantify the effect of Webassign, indications are that Webassign contributes to improved performance. In a 2014 survey, 98\% of students indicated that Webassign definitely or probably had a positive impact on improving their knowledge.

Completing assignments on the Webassign platform is, in essence, formative assessment. The objective is to monitor student learning to provide continuous feedback that can 
be used by students to determine their progress in the course and to improve their learning. The Webassign component of a course normally contributes a fairly small percentage to the semester mark, between $4 \%$ and $7 \%$, as there is no security check on doing the assignments.

The department has been using Webassign since 2010 and it has been used increasingly since then.

\subsubsection{Regular online quizzes in the learning management system (LMS)}

Another form of formative assessment used in HIMs is that of online quizzes set in the learning management system (LMS). When used, a weekly quiz is set to be completed by a due date. The advantages are similar to those of using Webassign - immediate feedback for both students and lecturers and no physical grading involved. An advantage of online quizzes over Webassign is that there is no cost attached to using it. However, a disadvantage is that a databank of questions needs to be compiled, which could be both costly and time consuming. It is also important to closely guard the quality and correctness of these homegrown questions. Security is an issue as there is no control over a student completing his own quiz or not consulting anyone.

As with Webassign, the format of the assessment is somewhat limiting. The type of questions that are available is mostly provided response, e.g., multiple-choice and multipleresponse questions. The only constructive response question format (that can be marked electronically) in the LMS is single numeric response questions. In Webassign, the possibilities are wider and include symbolic responses.

Online quizzes are inherently retrospective - they are written after initial learning has taken place. Combining a Webassign assignment preceding the tutorial session with an online quiz after the session is suited to the learning process.

Online quizzes in the LMS have been conducted since 2008.

\subsection{Readily available support}

\subsubsection{Supplemental Instruction tutor system}

A costly initiative is that of Supplemental Instruction(SI), that was offered for a few first year HIM courses for engineering students for the period 2011-2012. SI is a widely used student academic assistance programme that increases student performance and retention.[35] The programme attempts to address students' needs in a holistic approach. Fundamental features of SI are that it is voluntary, student-driven and focuses on high-risk courses rather than highrisk students. Delivery of SI begins in the first week of lectures, it integrates study skills with content and it encourages peer collaborative learning. SI sessions are open to all students, irrespective of academic capability. Central to the activities of the SI programme are the SI leaders. SI leaders are senior students themselves, who have successfully completed the course and have received intensive training in the principles of non-directive facilitation of small groups. They offer regular out-of-class, peer-facilitated sessions after attending the lectures themselves, thereby integrating content with learning skills and study strategies. The implementation of the SI programme for large groups of students is not an easy process as reported on in [35].

The ideals of the SI system are indisputable but the gain for effort is debatable. The SI system requires of the coordinator and leaders to adhere to prescribed procedures and leaves little room for deviating from these. For example, students, fresh from school and flooded with compulsory tasks, find it hard to keep up with these and voluntary activities 
Table 2. Comparison between SI and non-SI students.

\begin{tabular}{lcc}
\hline & SI & Non-SI \\
\hline Number of students & 394 & 828 \\
Pass percentage (all students) (\%) & 76.1 & 74.8 \\
Average mark (all students) (\%) & 57.8 & 58.2 \\
Pass percentage (lower performing students) (\%) & 73.6 & 72.5 \\
Average mark (lower performing students) (\%) & 55.3 & 55.9 \\
\hline
\end{tabular}

are the first they let go of. Timely identification of students who are at risk is difficult in the traditional model and students can often only be referred for voluntary correctional instruction after scoring of the first examination.

Data were collected for the 10 SI sessions presented for the first semester of 2010 , to a group of more than 1200 students. Two groups are distinguished:

- students who attended at least six SI sessions (referred to as SI students);

- students who attended at most five SI sessions (referred to as non-SI students).

Table 2 gives the pass percentages and the average marks for the two groups, based on the final marks obtained in the course.

From Table 2, it appears that both the pass percentage and average marks of the regular SI session attendees are not meaningfully different from those students who do not attend. It is hence clear that this intervention does not justify the financial cost and additional human resource investment.

It is also of interest that the lower performing students, students with an aggregate of less than $74 \%$ and for whom the SI sessions were specifically intended, do not seem to benefit significantly from the SI sessions as the pass percentage as well as the average percentages do not differ significantly. The SI system is resource intensive and with the functioning difficulties experienced the decision was taken to let go of the system. It was replaced by a more informally structured tutoring system where attendance of poor performing students is enforced.

The SI tutoring system was implemented in the years 2010-2012 only.

\subsubsection{The one-four assistant}

Since 2010, a one-four assistant support, a one-stop service offered, is an additional consultation and tutorial facility available for students to drop in at any time from Monday to Friday between 13:00 and 16:00 (hence the name). The objective with this service is to provide a consultation and tutorial facility where students drop in to consult on a one-to-one basis. The intention is to provide students with a relaxed environment for personal, timeous consultation. This service is not a novel idea - many other universities employ such a service, sometimes called a hot seat, hotline or help desk.[36]

The one-four assistant supports students by clarifying concepts misunderstood during lectures and by addressing problems, mathematical or otherwise. Again, the success of this initiative is hard to measure, but from regular attendance numbers it is clear that the service answers in a need. Attendance varies through the semester and is more prevalent during tests and examination periods and is also dependent on the staff member responsible for the one-four facility. Some students frequent the service repeatedly, clearly forming 
a bond with the assistant whereas other students see no need for consultation. The same phenomenon is experienced by lecturers during their office consultation hours.

\subsection{Repeated exposure}

\subsubsection{Overview lectures}

At the end of every week, a session is presented by an experienced teaching assistant, in which an overview of the week's work is given. These lectures are presented for each of the HIMs on first year level. Overview lectures are voluntary and are reasonably well attended by a cross section of students. They were introduced in 2009, when there was a crisis with poor performance on the new intake of first year students. These sessions were particularly popular, so much so that they were extended to other courses and adopted by some other departments in the faculty. It is not possible to schedule a time slot that will suit everyone and, therefore, some students will necessarily be excluded. Attendance numbers are in the order of $10 \%$ of students, which at first may appear to be low, but this initiative is targeted towards the lower end of the performance scale and serves a need.

A survey on the impact of overview lectures on student learning, completed by 98 students, indicated that

- about $70 \%$ are positive about the lectures;

- more than $80 \%$ would encourage other students to attend;

- the vast majority regard these lectures as better than normal lectures.

Although it is difficult to determine the effect of the overview lectures, the success could be measured by the attendance. The attendance numbers are fair throughout the semester with an increase in attendance numbers shortly before the term tests. The fact that these lectures are presented by a junior staff member, someone that students can associate with, is perhaps also a draw card.

\subsubsection{Summer and winter schools}

A dilemma experienced by probably all universities in South Africa is that pass rates are expected to be maintained and even improved on despite the under-preparedness of students and without lowering of standards. Although students initially experience difficulties in adjusting to the pace and content level of mathematics at university, there generally is an improvement in performance during the run of the semester. A particular category of students that has been identified is the group of students with a final mark of between $40 \%$ and $50 \%$ (50\% being the pass mark). The final mark is calculated as the average between the semester mark (the aggregate mark over a period of 13 weeks) and the examination mark. These students are considered to be capable of attaining the pass mark of $50 \%$, given more time and tuition. In most HIMs, these students will lose a full year if they do not pass the course. For this reason, summer and winter schools were put into place.

The aim of the summer/winter school is to provide a student, who has failed a course in the semester programme, with an opportunity to pass the course before the beginning of the following semester, thereby assisting the student to progress through the intended degree programme with minimum delay. 
Table 3. Average summer/winter school data over the years 2008-2013.

\begin{tabular}{|c|c|c|c|c|}
\hline Course & $\begin{array}{l}\text { Average number } \\
\text { of students in the } \\
\text { course }\end{array}$ & $\begin{array}{l}\text { Average number } \\
\text { of students in } \\
\text { winter/summer } \\
\text { school }\end{array}$ & $\begin{array}{l}\text { Average pass rate } \\
\text { in winter/summer } \\
\text { school course }(\%)\end{array}$ & $\begin{array}{c}\text { Average increase } \\
\text { in total pass rate } \\
\text { after winter/ } \\
\text { summer school } \\
(\%)\end{array}$ \\
\hline $\begin{array}{l}\text { Semester } 1 \\
\text { calculus }\end{array}$ & 1267 & 91 & 91 & 6.5 \\
\hline $\begin{array}{l}\text { Semester } 2 \\
\text { calculus }\end{array}$ & 1056 & 123 & 91 & 10.4 \\
\hline Linear algebra & 1119 & 70 & 89 & 5.8 \\
\hline
\end{tabular}

Summer and winter schools have been presented during the recess period between consecutive semesters, immediately following on the recently presented course. The summer and winter school model comprises presentation of the course over a period of eight days with intense tuition, often concluded by a test at the end of the day on the day's work. Students pay tuition fees for these courses. At the end of the eight-day period students do an examination. Experienced lecturers present summer and winter schools and they are remunerated additionally.

Summer and winter schools have proven to be successful for a variety of reasons. First, the group is selected for having the potential to pass; second, a student can devote his undivided attention to the subject; and third, students are fully aware of the implication on their future studies of failing the course again. The pass rates for the summer and winter schools normally exceed $90 \%$ and it is generally perceived as an extremely successful intervention. Since summer/winter schools have been presented for quite a number of HIM courses over the last six years, we summarize the impact of these courses in Table 3.

The data in Table 3 clearly indicate that the winter/summer school has a positive impact on the overall pass rate, enabling a significant number of students to progress through their programmes without delay.

Summer schools are, of course, not a novel idea, they are offered worldwide. Our summer/winter schools, however, are fairly unique with regard to target audience and format. It has to be pointed out that critics question the long-term retention of information that has been acquired at such an accelerated pace.[37,38] It could be counter-argued that students in our case had been exposed to the knowledge over a longer period before and only needed a strong impetus to pass. The summer and winter school initiative has been running since 2008 and because of its success will be continued indefinitely.

\section{Effect of HIM interventions}

As an indication of the success of the interventions described above, data on two of the largest HIM courses (first year engineering mathematics and first year mainstream mathematics) are presented in Table 4. Final pass percentages are calculated from the sum of students who passed the final examination, the supplementary examination and the summer/winter school, as a fraction of the final examination entrants. The upward trend over the period 2009-2013 is indicative of the success of the interventions.

From Table 4, it is clear that there is a steady improvement in pass rates for both the first year engineering course and the mainstream mathematics course. The improvement 
Table 4. Pass percentages 2009-2013 in first year engineering mathematics and first year mainstream mathematics.

\begin{tabular}{ccc}
\hline & Engineering (\%) & Mainstream (\%) \\
\hline 2009 & 71 & 56 \\
2010 & 81 & 58 \\
2011 & 84 & 72 \\
2012 & 84 & 74 \\
2013 & 88 & 73 \\
\hline
\end{tabular}

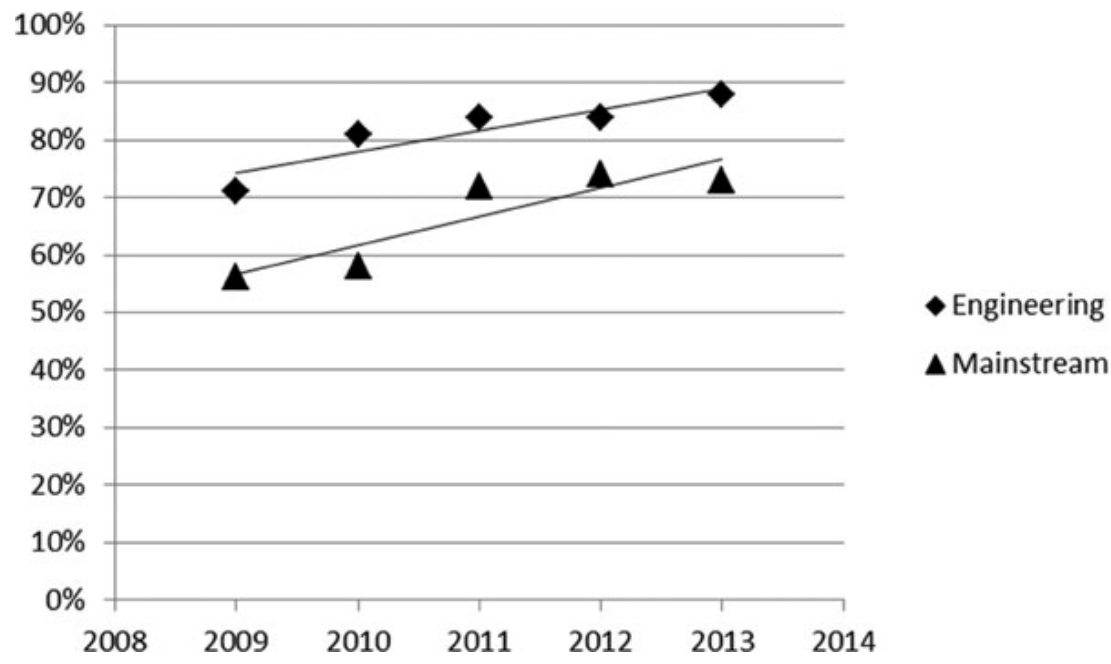

Figure 1. Pass percentages 2009-2013 in first year engineering mathematics and first year mainstream mathematics.

is impressive since high student numbers are involved. In 2014, the first year engineering group consisted of about 1300 students whereas the mainstream mathematics group had 800 students.

Figure 1 shows a plot of the data, with the trend lines illustrating the improvement in pass rates.

\section{Conclusion}

It is a common occurrence to develop initiatives at university level to improve the first year experience. Successful transition from the school environment to the tertiary environment is pivotal and most universities address the issue as best as possible. Yet it is also important to insure progress of students through the first year, offering the necessary support and designing appropriate activities.

In mathematics, problems associated with the transition are perhaps exacerbated because of the procedural approach followed at school level as well as the practice of examination coaching. Students have to undergo a change in thinking approach, from procedural to more conceptual, and a culture of independent learning needs to be fostered.

The first year experience is, therefore, multifaceted and each of the different devised activities seeks to address one of these facets. 
This paper offers a framework, founded in literature, in which five key facets are identified that collectively have the aim to ease the way into university and through the first year. The framework results in a model that is replicable for similar contexts. Individual activities and initiatives can be grouped along the facets of the framework.

Some of the nine interventions discussed in this paper were more effective than others. The intervention that is probably the most successful is the introduction of summer and winter schools. The intervention that we experienced as least successful is the SI system that was introduced as a tutorial model.

The University of Pretoria's mathematics department is showcased in this paper as an example of a department that actively deploys activities to better the first year experience. Not only are these initiatives classified by means of the framework but each is evaluated for the gains to student progress. The successful implementation of this model at a researchintensive university serves as an example on how student retention can be improved, even at an institution where research is paramount. The paper aims to contribute to the knowledge base of a successful first year experience that is currently widely topical.

\section{Acknowledgement}

We acknowledge support from the University of Pretoria's SoTL fund for this research.

\section{Disclosure statement}

No potential conflict of interest was reported by the authors.

\section{References}

[1] Engelbrecht J, Harding A, Phiri P. Are OBE trained students ready for university mathematics? Pythagoras. 2010;72:3-13.

[2] Scott I, Yeld N, Hendry J. A case for improving teaching and learning in South African higher education. Pretoria: Council on Higher Education; 2007. (Higher Education Monitor No. 6).

[3] Benford R, Gess-Newsome J. Factors affecting student academic success in gateway courses at Northern Arizona University. Flagstaff (AZ): Center for Science Teaching and Learning, Northern Arizona University; 2006. (ERIC Document No ED495693).

[4] Boughey C. Lessons learnt from academic development movement in South African Higher Education and their relevance for student support initiatives in the FET college sector. Commissioned Report. Cape Town: Human Sciences Research Council; 2005.

[5] Cloete N, Bunting I. Higher education transformation: assessing performance in South Africa. Pretoria: CHET; 2000.

[6] Ogude NA, Kilfoil W, Du Plessis G. An institutional model for improving student retention and success at the University of Pretoria. Int J First Year High Educ. 2012;3(1):14. doi:10.5204/intjfyhe.v3i1.97.

[7] Dell S. South Africa: universities face more under prepared students. Business Day, Issue 45. 2010 [cited 2012 April 17]. Available from: http://www.universityworldnews.com/ article.php?story $=20100114190733824$.

[8] Engelbrecht J, Harding A. The impact of the transition to outcomes-based teaching on university preparedness in mathematics in South Africa. Math Educ Res J. 2008;209(2):51-70.

[9] Akoojee S, Nkomo M. Access and quality in South African higher education: the twin challenges of transformation. S Afr J Higher Educ. 2007;21(3):385-399.

[10] Zewotir T, North D, Murray M. Student success in entry level modules at the University of KwaZulu-Natal. S Afr J Higher Educ. 2011;25(6):1233-1244.

[11] University of Pretoria. Strategic plan: the vision, mission and plan of the university for 2025. 2011 [cited 2014 June 9]. Available from: http://web.up.ac.za/sitefiles/ file/publications/2012/eng/STRATEGIC_PLAN_(V11)_13\%20Feb.pdf. 
[12] Lawson D, Croft T, Halpin M. Good practice in the provision of mathematics support centres. Learning and teaching in mathematics, statistics and operations research, 3/01. Coventry: LTSN Maths, Stats and OR Network; 2001.

[13] Anthony G. Factors influencing first-year students' success in mathematics. Int J Math Educ Sci Technol. 2000;31(1):3-14.

[14] Sutherland R, Dewhurst H. Mathematics education framework for progression from 16-19 to HE. Bristol: University of Bristol Graduate School of Education; 1999.

[15] Tinto V. Leaving college: rethinking the causes and cures of student attrition. Chicago (IL): The University of Chicago Press; 1993.

[16] Lemmens J. Students' readiness for university education [unpublished doctoral thesis]. Pretoria: University of Pretoria; 2010.

[17] Schlossberg NK, Waters EB, Goodman J. Counseling adults in transition: linking practice with theory. 2nd ed. New York: Springer Publishing Company Inc.; 1995.

[18] Bean J, Eaton S. A psychological model of college student retention. In: Braxton J, editor. Reworking the departure puzzle: new theory and research on college student retention. Nashville, TN: Vanderbilt Universities Press; 2000. p. 48-61.

[19] Conley D. Towards a more comprehensive conception of college readiness. A report prepared for the Bill and Melinda Gates Foundation. Eugene (OR): Educational Policy Improvement Center; 2007. [cited 2015 February 2]. Available from: http://www.smallschoolsproject. org/PDFS/meetings/conley_college_ready.pdf.

[20] Braxton JM. Reinvigorating theory and research on the departure puzzle. In: Braxton JM, editor. Reworking the student departure puzzle. Nashville (TN): Vanderbilt University Press; 2000. p. 257-274.

[21] Sedlacek WE. The case for noncognitive measures. In: Camara WJ, Kimmel EW, editors. Choosing students: higher education admissions tools for the 21st Century. Mahwah (NJ): Lawrence Erlbaum Associates Publishers; 2005. p. 177-193.

[22] Braxton JM, Hirschy AS, McClendon SA. Understanding and reducing college student departure. San Francisco: Jossey-Bass, 2003.

[23] James R, McInnis C, Devlin M. Assessing learning in Australian universities. Melbourne: Centre for the Study of Higher Education; 2002. [cited 2015 May 20]. Available from: http://www.cshe.unimelb.edu.au/assessinglearning/.

[24] Gill O, Mac An Bhaird C, Ni Fhloinn E. The origins, development \& evaluation of mathematics support services. Irish Math Soc Bull. 2010;66:51-63.

[25] Maynooth University. Mathematics support centre. [cited 2015 May 20]. Available from: http://supportcentre.maths.nuim.ie/testimonials.

[26] Grehan M, Macan Bhaird C, O’Shea A. Why do students not avail themselves of mathematics support? Res Math Educ. 2011;13(1):79-80.

[27] Oakley B. How I rewired my brain to become fluent in math. Nautilus Quarterly Newsletter. 2014 October [cited 2015 May 19]. Available from: http://nautil.us/issue/17/big-bangs/how-irewired-my-brain-to-become-fluent-in-math-rd

[28] Leung FKS. In search of an East Asian identity in mathematics education. Educ Stud Math. 2001;47(1):35-51.

[29] Engelbrecht J. Adding structure to the transition process to advanced mathematical activity. Int J Math Educ Sci Technol. 2010;41(2):143-154.

[30] Fhloinn EN, Perkin G. Novel approaches to refresher courses in basic mathematics. MSOR Connect. 2010;9(4):3-6.

[31] Burn HE, Baer EMD, Wenner JM. Embedded mathematics remediation using the math you need, when you need it: a 21 st-century solution to an age-old problem. About Campus. 2013;18(5):22-25.

[32] Yeld N. The interface between schools and universities: findings from the National Benchmark Test project. Paper presented at: The CHEC/PGWC Joint Regional Workshop on Student Performance; October 2009; School of Public Health, University of the Western Cape. [cited 2013 October 15]. Available from: http://www.chec.ac.za/reports/Reports\%20PDFs/ 10\%20Report $\% 20$ on\%20Student \%20Perfomance\%20seminar\%202009.pdf.

[33] Swaner L, Brownell J. Outcomes of high impact practices for undeserved students. A review of the literature. Prepared for the Association of American Colleges and Universities; 2009. [cited 2013 June 8]. Available from: http://www.aacu.org/inclusive_excellence/documents/ ProjectUSALitReviewrevisedMar10.pdf. 
[34] Kaufmann J. Enhanced webassign. Andover: Cengage Learning; 2010.

[35] Harding A, Engelbrecht JC, Verwey A. Implementing Supplemental Instruction (SI) for a large group in mathematics. Int J Math Educ Sci Technol. 2011;42(7):847-856.

[36] Means B. Technology and education change: focus on student learning. J Res Technol Educ. 2010;42(3):285-307.

[37] Anastasi JS. Full-semester and abbreviated summer courses: an evaluation of student performance. Teach Psychol. 2010;1:19-22.

[38] Kucsera JV, Zimmaro DM. Comparing the effectiveness of intensive and traditional courses. Coll Teach. 2010;58(2):62-68. 